\title{
Aplicabilidade da audiodescrição e inclusão de áudios nos resumos dos artigos do Portal de Periódicos Científicos da UNICAMP
}

\author{
SANTOS, Gildenir Carolino ${ }^{1^{*}}$ \\ TARTAROTTI, Roberta Cristina Dal'Evedove ${ }^{2^{* *}}$ \\ ${ }^{1,2}$ Universidade Estadual de Campinas. Sistema de Bibliotecas - Brasil \\ ORCID ID: https://orcid.org/0000-0002-4375-6815* \\ ORCID ID: https://orcid.org/0000-0002-0246-4971**
}

\begin{abstract}
Resumo
A proposta deste trabalho é apresentar o projeto de extensão submetido ao edital da PróReitoria de Extensão e Cultura da Universidade Estadual de Campinas (UNICAMP), tendo como objetivo a contratação de especialistas em Libras e em Audiodescrição para realizar a transcrição dos resumos dos artigos dos periódicos do Portal de Periódicos da UNICAMP em áudio no site do Portal para pessoas com deficiência. Serão utilizados recursos tecnológicos disponíveis no próprio computador (gravador, editor de texto, Google Suites e OJS). Assim, com a execução deste projeto, será possível o atendimento imediato de todos os periódicos do Portal. Reitera-se a relevância da disponibilização dos recursos informacionais aos usuários com deficiência tanto da comunidade acadêmica quanto externa, contribuindo para a elaboração de uma política institucional de inclusão e acessibilidade na Universidade.
\end{abstract}

Palavras-chave: Inclusão científica. Audiodescrição. Periódicos acessíveis.

\section{Applicability of audio description and inclusion of audios in the abstracts of the} articles of the Portal of Scientific Journals of UNICAMP

\begin{abstract}
The purpose of this work is to present the extension project submitted to the notice of the Pro-Rector of Extension and Culture of the University of Campinas (UNICAMP), with the objective of hiring specialists in Libras and Audio description to transcribe the abstracts of the journals of the Journals of UNICAMP in audio on the portal website for people with disabilities. Technological resources available on the computer itself (recorder, text editor, Google Sites and OJS) will be used. Thus, with the execution of this project, it will be possible to immediately attend all journals of the Portal. Reiterate the relevance of making information resources available to users with disabilities both from the academic and external community, contributing to the elaboration of an institutional policy of inclusion and accessibility in the University.
\end{abstract}

Keywords: Scientific inclusion. Audio description. Accessible journals.

\section{Aplicabilidad de la audiodescr alejandría e inclusión de audios en los resúmenes de los artículos del Portal de Revistas Científicas de UNICAMP}

\section{Resumen}

El objetivo de este trabajo es presentar el proyecto de ampliación presentado al aviso del Pro-Rector de Extensión y Cultura de la Universidad Estatal de Campinas (UNICAMP), con el objetivo de contratar especialistas en Libras y Descripción de Audio para transcribir los resúmenes de las revistas de las Revistas de UNICAMP en audio en la página web del Portal para personas con discapacidad. Se utilizarán los recursos tecnológicos disponibles en el propio ordenador (grabador, editor de texto, Sitios de Google y OJS). Así, con la ejecución de este proyecto, será posible asistir inmediatamente a todas las revistas del Portal. Reiterase la pertinencia de poner a disposición de los usuarios con discapacidad recursos de información tanto de la comunidad académica como externa, contribuyendo a la elaboración de una política institucional de inclusión y accesibilidad en la Universidad. Palabras clave: Inclusión científica. Descripción de audio. Revistas accesibles. 


\section{Introdução}

A proposta deste trabalho é apresentar o projeto de extensão submetido ao edital da PróReitoria de Extensão e Cultura (PROEC) da Universidade Estadual de Campinas (UNICAMP), tendo como objetivo a contratação de especialistas em Libras e em Audiodescrição para realizar a transcrição dos resumos dos artigos dos periódicos do Portal de Periódicos da UNICAMP em áudio (MPEG) no site do Portal para pessoas com deficiência. Considerando-se que o trabalho de conversão e transcrição de informações requer qualidade no sentido de respeitar a integridade do conteúdo bibliográfico do documento a ser transcrito, e que há poucos recursos humanos e financeiros para este projeto, o edital da PROEC vem ao encontro desta necessidade, visando o atendimento destes usuários.

De acordo com a literatura, a audiodescrição é um recurso que possibilita a tradução de imagens em palavras, permitindo que pessoas cegas ou com baixa visão consigam compreender conteúdos audiovisuais ou imagens estáticas, como figuras, gráficos, tabelas, filmes, fotografias, peças de teatro, entre outros. A informação sonora é um recurso fundamental para que deficientes visuais ou com baixa visão possam compreender conteúdos audiovisuais. Nesse sentido, a audiodescrição é um instrumento de inclusão científica, que permite o acesso e disponibilização plena de pessoas com deficiência visual à produção científica em seus diversos campos do conhecimento. Além das pessoas com deficiência visual, amplia também o entendimento de pessoas com deficiência intelectual, idosos e disléxicos (MOTTA, 2020; TARTAROTTI; LANDIM; MARTINS, 2019).

\section{Metodologia}

O projeto terá como metodologia a contratação de especialistas em Libras e em Audiodescrição para realizar a transcrição dos resumos dos artigos dos periódicos do Portal de Periódicos Eletrônicos Científicos (PPEC) da Universidade Estadual de Campinas (UNICAMP) em áudio/vídeo e realização da audiodescrição do site do Portal para pessoas com deficiência (PCD).

Atualmente o PPEC conta com 31 títulos credenciados e 15 títulos em sua incubadora com os periódicos menos qualificados para ingressar no Portal (aproximadamente 16 mil artigos indexados). Assim, com a execução deste projeto, será possível o atendimento imediato de todos os periódicos do Portal (UNIVERSIDADE ESTADUAL DE CAMPINAS, 2020). 
Cabe ressaltar que não serão adquiridas ferramentas para tais serviços, sendo utilizados recursos tecnológicos e plataformas disponíveis nos próprios computadores instalados na Sala de Pesquisa da Biblioteca Central César Lattes ou trazidos pelos profissionais a serem contratados, tais como: pacote MS-Office; gravador de voz; câmera do smartphone para a geração de vídeo; Google Sites (página com resumo) e disponibilização no sistema de gerenciamento dos periódicos - OJS.

Assim, com a execução deste projeto, será possível o atendimento imediato de todos os periódicos do Portal. Cabe destacar o início de um projeto-piloto com um dos periódicos do Portal, cuja publicação é a RDBCI: Revista Digital de Biblioteconomia e Ciência da Informação, edição 2020, possibilitando a gravação dos resumos em áudio de 24 artigos publicados, disponíveis no site ${ }^{1}$ da revista.

Após a aprovação do projeto, será realizada a seleção de um profissional especialista em Libras e um profissional especialista em Audiodescrição para execução das atividades.

\section{Resultados e Discussão}

Espera-se que com este projeto seja possível garantir o acesso à produção dos periódicos científicos à comunidade de pessoas com deficiência. Acredita-se que a partir do momento em que tivermos os resumos de artigos em áudio/vídeo e audiodescrição para as pesquisas deste público menos favorecido, haverá um aumento nos rankings de acesso ao Portal, tendo em vista que atualmente o Portal de Periódicos ultrapassa 1 milhão e 300 mil acessos e downloads ${ }^{2}$ por ano.

\section{Considerações finais}

Como considerações finais, reitera-se a relevância da disponibilização dos recursos informacionais aos usuários com deficiência tanto da comunidade acadêmica quanto externa, contribuindo para a elaboração de uma política institucional de inclusão e acessibilidade na Universidade.

\footnotetext{
${ }^{1}$ Disponível em: https://periodicos.sbu.unicamp.br/ojs/index.php/rdbci/issue/view/1645 Acesso em: 15 jul. 2020.

2 Disponível em: http://143.106.108.44:3000/public/dashboard/17afbb9c-d3a9-4a86-aa21-d134238a6389. Acesso em: 15 jul. 2020 


\section{Referências}

MOTTA, L. M. V. D. M. Audiodescrição: recurso de acessibilidade para a inclusão cultural das pessoas com deficiência visual. 2020. Disponível em: http://vercompalavras.com.br/pdf/artigoaudiodescricao-recurso-de-acessibilidade.pdf. Acesso em 15 jul. 2020.

TARTAROTTI, R. C. D.; LANDIM, F. A.; MARTINS, V. dos S. G. Audiodescrição como recurso de acessibilidade cultural: a experiência do laboratório de acessibilidade (LAB) da Biblioteca Central César Lattes (BCCL) da UNICAMP. Sínteses: Revista Eletrônica do SimTec, n.7, e019285, 2019. DOI: https://doi.org/10.20396/sinteses.v0i7.11404.

UNIVERSIDADE ESTADUAL DE CAMPINAS. Portal de Periódicos Eletrônicos Científicos. Sobre o Portal. Disponível em: https://periodicos.sbu.unicamp.br/ppec/sobre/. Acesso em: 16 jul. 2020.

\section{${ }^{1}$ Gildenir Carolino Santos (Campinas, São Paulo, Brasil)}

Bibliotecário pela PUC-Campinas. Mestre e Doutor em Educação pela UNICAMP. Responsável pelo Portal de Periódicos Eletrônicos Científicos da UNICAMP.

Contribuição de autoria: elaboração do projeto, escrita.

Lattes: http://lattes.cnpq.br/1221773207784315

E-mail: gilldenir@unicamp.br

${ }^{2}$ Roberta Cristina Dal'Evedove Tartarotti (Campinas, São Paulo, Brasil)
Bibliotecária pela UNESP. Mestre em Ciência, Tecnologia e Sociedade pela UFSCar; Doutora em Ciência da
Informação pela UNESP. Colaboradora do Centro de Recursos de Aprendizagem da Biblioteca Central da
UNICAMP.
Contribuição de autoria: revisão e edição
Lattes: $\underline{\text { http://lattes.cnpq.br/0013338820189150 }}$
E-mail: robertat@ $@$ unicamp.br

Avaliador(a) responsável: Heloisa Fleury

\section{Como citar este artigo:}

SANTOS, Gildenir Carolino, TARTAROTTI, Roberta Cristina Dal'Evedove. Aplicabilidade da audiodescrição e inclusão de áudios nos resumos dos artigos do Portal de Periódicos Científicos da UNICAMP. In: ABEC Meeting Live, 2020. Anais... São Paulo: Associação Brasileira de Editores Científicos, 2020. DOI: http://dx.doi.org/10.21452/abecmeeting2020.04 